\title{
Impacts of spatial and environmental differentiation on early Palaeozoic marine biodiversity
}

\section{Penny, Amelia}

2019-12

Penny , A \& Kroger , B 2019 , ' Impacts of spatial and environmental differentiation on early

Palaeozoic marine biodiversity ' , Nature Ecology \& Evolution , vol. 3 , no. 12 , pp. 1655-+ . https://doi.org/10.1038/s

http://hdl.handle.net/10138/325369

https://doi.org/10.1038/s41559-019-1035-7

unspecified

acceptedVersion

Downloaded from Helda, University of Helsinki institutional repository.

This is an electronic reprint of the original article.

This reprint may differ from the original in pagination and typographic detail.

Please cite the original version. 


\section{Impacts of spatial and environmental differentiation on early Palaeozoic marine}

2 biodiversity

3

4 Amelia Penny $^{1 *}$, Björn Kröger ${ }^{1}$

5

$6 \quad{ }^{1}$ Finnish Museum of Natural History, P.O.Box 44 (Jyrängöntie 2), 00014 University of Helsinki,

$7 \quad$ Finland

8 *amelia.penny@helsinki.fi

9

10

11

12

13

14

15

16

17

18

19

20

21

22

23 


\section{Abstract}

25 The unprecedented diversifications in the fossil record of the early Palaeozoic (541-419 Ma)

26 increased both $\alpha$ (within-sample) and $\gamma$ (global) diversity, generating considerable ecological

27 complexity. Faunal difference ( $\beta$ diversity), including spatial heterogeneity, is thought to have

28 played a major role in early Palaeozoic marine diversification, though $\alpha$ diversity is the major

29 determinant of $\gamma$ diversity through the Phanerozoic. Drivers for this Phanerozoic shift from $\beta$ to $\alpha$

30 diversity are not yet resolved. Here, we evaluate the impacts of environmental and faunal

31 heterogeneity on diversity patterns using a global spatial grid. We present early Palaeozoic

32 genus-level $\alpha, \beta$ and $\gamma$ diversity curves of molluscs, brachiopods, trilobites and echinoderms and

33 compare them with measures of spatial lithological heterogeneity, which is our proxy for

34 environmental heterogeneity. We find that $\alpha$ and $\beta$ diversity are associated with increased

35 lithological heterogeneity, and that $\beta$ diversity declines over time while $\alpha$ increases. We suggest

36 that the enhanced dispersal of marine taxa from the Middle Ordovician onwards facilitated

37 increases in $\alpha$ diversity by encouraging the occupation of narrow niches and increasing the

38 prevalence of transient species, simultaneously reducing spatial $\beta$ diversity. This may have

39 contributed to a shift from $\beta$ to $\alpha$ diversity as the major determinant of $\gamma$ diversity increase over

40 this critical evolutionary interval.

\section{Introduction}

43 The early Palaeozoic fossil record shows tremendous diversification, often conceptualized as two

44 episodes: the Cambrian Explosion (CE) and the Great Ordovician Biodiversification Event

45 (GOBE), with contrasting impacts on global diversity and palaeoecology ${ }^{1-10}$. The CE includes

46 the appearance of most metazoan phyla, and widespread metazoan burrowing, macropredation, 
47 motility and reef building ${ }^{11}$. During the GOBE, marine family- and genus-level diversity rose,

48 increasing ecological tiering, plankton diversity and bioturbation, and changing the composition

49 of reef communities ${ }^{2,8}$. However, the mechanisms driving early Paleozoic diversity accumulation

50 remain elusive ${ }^{12}$.To address this issue, $\alpha, \beta$ and $\gamma$ diversity are widely used to quantify the

51 contributions of within-sample diversity $(\alpha)$ and faunal heterogeneity $(\beta)$ to total diversity $(\gamma)$

52 (e.g. ${ }^{1,13-15}$, see review in ${ }^{16}$ ).

$54 \gamma$ and $\alpha$ diversity rose during the early Palaeozoic ${ }^{13,17,18}$, but the role of $\beta$ diversity is less

55 obvious. Diversity may be measured in spatial or environmental units, including continents,

56 depositional basins, rock outcrops, palaeoenvironments or formations, which here means rock

57 units with formally described characteristics which distinguish them from surrounding rocks.

58 One recent study of within-formation diversity found that during the initial stages of

59 diversifications, including in the early Palaeozoic, $\gamma$ diversity is driven by $\beta$ diversity until it

60 saturates ${ }^{14}$. Then, $\alpha$ diversity becomes the main $\gamma$ diversity driver, as predicted by theoretical

61 models $^{19}$.

63 While within-formation $\beta$ diversity focuses on environmental faunal differentiation, geographic $\beta$

64 diversity (geodisparity ${ }^{13,20}$ ) may have played an important role in early Palaeozoic

65 diversification. During the CE, geodisparity increased in concord with continental

66 fragmentation ${ }^{13}$, and during the GOBE it may have been affected by dispersal, which facilitated

67 speciation $^{21,22}$ and geographic range expansion ${ }^{23} . \beta$ diversity patterns within and between

68 palaeocontinents suggest that at regional scales, Ordovician geographic $\beta$ diversity declined as

69 taxa dispersed and integrated into communities, increasing $\alpha$ diversity ${ }^{24}$. 
71 Here, we assess the impact of spatial and environmental faunal differentiation at global scale. We

72 adopt a spatial approach to $\beta$ diversity, which should capture the effects of large-scale processes

73 such as continental fragmentation, dispersal and integration of taxa between areas, the

74 development of climatic gradients, and biogeographic change, which are implicated in early

75 Palaeozoic diversification ${ }^{13,21,25,26}$. We also evaluate the role of faunal differentiation between

76 lithologies in generating geographic $\beta$ diversity. This spatial approach complements studies of

77 diversity dynamics based on palaeoenvironments (e.g. ${ }^{1}$ ) or on collections from lithological

78 formations (e.g. $\left.{ }^{14}\right)$.

80 We constructed global Cambrian-Silurian genus-level geographic $\alpha$ and $\beta$ diversity curves of

81 echinoderms, trilobites, brachiopods and molluscs, using equal-area hexagonal grids of side 111

$82 \mathrm{~km}$. This time window includes the CE and GOBE, as well as the Hirnantian extinction. We use

83 additive $\beta$ diversity partitioning to evaluate the contributions of taxon replacement and loss to $\beta$

84 diversity, as a means of evaluating the impact of dispersal. We also test the hypothesis that rising

$85 \alpha$ diversity during the Cambrian-Silurian is related to the development of more heterogeneous

86 habitats, and that faunal and lithological $\beta$ diversity are linked. Consideration of both

87 environmental and spatial faunal differentiation is essential for resolving the mechanisms driving 88 early Palaeozoic diversification.

\section{Results}

91 After rising in the early Cambrian, $\beta$ diversity estimates show generally high values across most

92 time bins, only dipping below 0.5 in the Hirnantian (Figure 1b). An initial sharp increase from 
93 the Terreneuvian to Cambrian Series 2 is in agreement with previously published work on

94 geographic $\beta$ diversity change in the Cambrian, which shows an initial increase followed by

95 decline, though our time bins do not permit detection of a later Cambrian recovery ${ }^{13}$. In the

96 Ordovician, $\beta$ diversity initially increases between the Tremadocian and the Floian, then

97 gradually declines towards the Katian, though it remains high (above 0.8). This is followed by a

98 sharp decline to 0.47 in the Hirnantian, coincident with the homogenization of faunas during the

99 Hirnantian mass extinction interval ${ }^{27}$. In sum, high $\beta$ diversity developed during the early

100 Cambrian, and showed a modest increase at the beginning of the Ordovician, before declining in

101 the Hirnantian and failing to recover fully in the Silurian. The overall pattern is consistent with

102 published geographic $\beta$ diversity curves for the Phanerozoic ${ }^{20}$. We find no correlation between $\beta$

103 diversity and the mean nearest-neighbour distance between grid cell centres in a time bin

104 (Kendall's $\tau=0.26, \mathrm{p}=0.25$, see Supplementary Information Table 1 ). Raw $\beta$ diversity

105 estimates are somewhat higher than the RAC (Relative Abundance Corrected) estimates, and

106 show a relatively flattened signal through time (Extended Data Figure 1, see Methods for details

107 on the RAC method).

108

109 Global $\gamma$ diversity increases initially, from the Terreneuvian to Cambrian Series 2. After a small

110 decline in the Miaolingian, $\gamma$ diversity peaks in the Darriwilian (Figure 1a) and declines steeply

111 in the Hirnantian, corresponding with the end-Ordovician mass extinction, before recovering

112 somewhat in the early Silurian. $\gamma$ diversity correlates moderately with $\alpha$ diversity over the

113 Cambrian to Silurian (Kendall's $\tau=0.46, \mathrm{p}=0.03$ ), and strongly with $\beta$ diversity (Kendall's $\tau=$ $114 \quad 0.59, \mathrm{p}<0.01)$. 
116 Mean $\alpha$ diversity increases steadily from the Terreneuvian to the Sandbian, with a minimum of

1175.6 in the Terreneuvian (Figure 1c). After peaking in the Sandbian, $\alpha$ diversity declines slightly

118 after the Hirnantian, before peaking in the Sheinwoodian-Homerian. However, the end of the

119 Silurian is marked by an $\alpha$ diversity decline. There is no correlation between $\alpha$ diversity and $\beta$

120 diversity (Kendall's $\tau=0.05, \mathrm{p}=0.86$ ).

121

122 Lithological variation within grid cells, represented by the mean number of formations within

123 grid cells, shows no pronounced increase through time (Figure 2a). We find a moderate positive

124 correlation between the number of formations within grid cells and $\alpha$ diversity (Kendall's $\tau=$

$1250.43, \mathrm{p}=0.04$; Figure 3).

126

127 We also calculated lithological heterogeneity between grid cells. We treated the lithological units

128 within grid cells as taxa and calculated the raw Sørensen dissimilarity, since this is a presence-

129 absence measure and we do not expect incomplete sampling to affect the numbers of formations

130 recorded. While there is no clear trend in lithological $\beta$ diversity through time and values are

131 high, we find a moderate positive correlation between taxonomic and lithological $\beta$ diversity

132 (Kendall's $\tau=0.39, \mathrm{p}=0.08$ ).

133

134 Nestedness is very low in the Cambrian and Ordovician, with almost all $\beta$ diversity reflecting 135 turnover (Figure 2b). However, in the Silurian, nestedness increases somewhat, accounting for 136 up to $16 \%$ of geographic $\beta$ diversity. 
138 While the number of grid cells containing sufficient data for analysis varies between time bins,

139 there is no statistically significant correlation between $\alpha, \beta$ or $\gamma$ diversity and the number of grid

140 cells (Kendall's $\tau=0.10, p=0.67$; Kendall's $\tau=0.18, p=0.44$; Kendall's $\tau=0.33, p=0.16$ ).

141 We infer that the number of samples is not a major influence on the diversity patterns recovered.

\section{Discussion}

144 Our results confirm that geographic $\beta$ diversity is an important component of $\gamma$ diversity increase 145 over the Cambrian - Ordovician. This is consistent with published data ${ }^{13}$, which suggest that the

146 CE occurred under conditions of continental fragmentation and, in the early Cambrian, involved

147 animals with low dispersal abilities, leading to a global assemblage of relatively low-diversity

148 but highly spatially differentiated communities. We also find that incomplete sampling flattens

149 raw geographic $\beta$ diversity fluctuations throughout the Cambrian-Silurian, making null models

150 and correction methods valuable for $\beta$ diversity studies over this interval (See Extended Data

151 Figure 1).

153 The results of our $\gamma$ diversity calculations are consistent with previous curves at stage level ${ }^{28}$.

154 The Middle Ordovician peak in $\gamma$ diversity appears decoupled from $\beta$ diversity, and instead rises

155 with $\alpha$ diversity (Figure 1). After the Floian, Ordovician increases in $\alpha$ and $\gamma$ diversity were not

156 matched by any corresponding increase in $\beta$ diversity, and as the GOBE proceeded in the

157 Darriwilian-Katian, $\beta$ diversity began to decline, suggesting faunal homogenisation. In the

158 Silurian, $\alpha$ diversity continues to increase while geographic $\beta$ diversity declines, suggesting that

159 enhanced $\alpha$ diversity may be related to the expansion of taxa into new areas. 
161 The recovery of $\gamma$ diversity after the Hirnantian involves an initial increase in $\beta$ diversity, after

162 which $\alpha$ diversity continues to rise as $\beta$ diversity declines. This may correspond to the high-

163 competition scenario of Hautmann $(2014)^{19}$, in which increases in $\beta$ diversity during

164 diversifications are transient, and cease when habitat contraction cannot continue. We find a

165 strong correlation between $\gamma$ and $\beta$ diversity over the whole time interval, but the curves suggest

166 a decoupling of $\gamma$ and $\beta$ diversity in the Middle-Late Ordovician and Silurian. This is consistent

167 with the conclusions of Hofmann et al. (2019) ${ }^{14}$, who found that within formations, $\beta$ diversity is

168 only a major driver of $\gamma$ diversity in the early stages of diversifications, particularly in the early

169 Palaeozoic. A similar pattern may apply to diversity patterns over spatially defined areas.

171 The decline in $\beta$ diversity during the Floian-Katian, in the main pulse of the GOBE, suggests that

172 the geographic range expansion of Ordovician marine invertebrates may have begun a gradual,

173 global faunal homogenization, a process both predicted and measured in the early

174 Palaeozoic ${ }^{23,29,30}$. The slight increase in nestedness reported here, particularly over the

175 Ordovician and Silurian, suggests that over this interval, assemblages within grid cells are

176 increasingly structured by patterns of colonisation followed by taxon loss ${ }^{31}$. The RAC $\beta$ diversity

177 curve also emphasizes the profound impact of the Hirnantian mass extinction interval on

178 geographic $\beta$ diversity, which almost halved over this time. Global faunal homogenization during

179 the Hirnantian has been documented in studies of between-formation $\beta$ diversity (e.g. ${ }^{27}$ ), but its

180 impact appears to have been more severe than previously recognized. Furthermore, we find that

181 the Hirnantian extinctions had a proportionally greater impact on geographic $\beta$ diversity than on

182 mean $\alpha$ diversity, emphasising their geographically heterogeneous effects. 
184 The positive correlation between lithological and taxonomic $\beta$ diversity likely illustrates the role

185 played by habitat differentiation in $\beta$ diversity; pairs of grids containing occurrences from

186 different lithological formations are more taxonomically distinct, and pairs containing

187 occurrences from the same formation are more taxonomically similar, though there is no clear

188 trend in lithological $\beta$ diversity over time. While lithological formations often comprise multiple

189 distinct habitats ${ }^{14}$, we have chosen to average the habitats recorded in a single lithological

190 formation and compare the number of formations occurring within grid cells. The positive

191 correlation between $\alpha$ diversity and the number of formations in a grid cell suggests that the

192 more formations occur within a grid, the higher its $\alpha$ diversity is likely to be. Although this

193 heterogeneity has both spatial and temporal components, the same effects are also present in the

194 diversity data, so we treat them as comparable. We suggest that in addition to community

195 differentiation between habitats, increased spatial environmental heterogeneity may have been

196 linked to increased $\alpha$ diversity over the Cambrian-Silurian.

197

$198 \alpha$ diversity is highest during the Silurian, but this is not solely due to the in situ origination of

199 new taxa, since $\beta$ diversity declined at this time, and $\gamma$ diversity peaked during the Middle

200 Ordovician. Here, we will first address the implications of the decline in $\beta$ diversity, and then go

201 on to discuss the implications of the disjunct between $\alpha$ and $\beta$ diversity for the mechanisms

202 driving $\alpha$ diversity.

203

204 At the large spatial scales used in this study, $\beta$ diversity patterns are affected by large-scale

205 physical features such geographic barriers and the development of a latitudinal diversity

206 gradient ${ }^{26,32-34}$, and our results suggest that they are also linked to changes in the spatial 
207 distribution of environments and in the ease of dispersal. The gradual decline in $\beta$ diversity from

208 the Middle Ordovician to the Silurian implies enhanced dispersal of genera between grid cells.

209 Geographic and environmental range expansion of taxa is expected as taxa age, and has been

210 documented in the Ordovician rock record ${ }^{23}$. This dispersal may have been enhanced from the

211 Ordovician onwards after the stepwise event known as the Ordovician Plankton Revolution ${ }^{3}$, a

212 diversification of planktic organisms from the late Cambrian onwards. In particular, both

213 molecular clock estimates and evidence from molluscan protoconchs suggest a Cambrian-

214 Silurian increase in the diversity of larval phases capable of feeding (planktotrophy), particularly

215 in the late Cambrian-early Ordovician ${ }^{35,36}$. Planktotrophic larvae can typically disperse for longer

216 than non-planktotrophic larvae and can be produced in larger numbers, since they do not require

217 an energetically expensive yolk as a food source ${ }^{37}$. The dispersal of planktic larvae over longer

218 distances provides a possible evolutionary mechanism for early Palaeozoic $\beta$ diversity decline.

220 Enhanced dispersal is also consistent with the slight increase in nestedness in the late Ordovician

221 and Silurian, which suggests that assemblages are increasingly constructed by the dispersal of

222 taxa into new areas followed by taxon $\operatorname{loss}^{31}$, rather than the isolation which leads to taxon

223 replacement (turnover). A quantitative examination of the role of dispersal in Ordovician genus

224 range expansion is outside the scope of this study, because of the general lack of preservation of

225 motile larval stages. However, widespread dispersal of brachiopod and trilobite taxa has been

226 documented through the Middle and Late Ordovician, and has been implicated as a driver for

227 speciation $^{22,38}$.

228

229 Dispersal could also explain the rise in $\alpha$ diversity at a time when $\beta$ was declining. One 
230 mechanism for increasingly close spatial packing of taxa is the rise of environmental spatial

231 heterogeneity at increasingly small scales, for example through the expansion of complex

232 environments such as reefs. This creates ever-smaller environmental niches for species to

233 occupy, increasing niche packing and consequently $\alpha$ diversity ${ }^{1,39}$. According to this model, taxa

234 cannot persist in environments where they are outcompeted in all niches; the more specialised

235 the niche, the less likely it is that an individual will find its niche when colonising a new area.

236 Enhanced dispersal abilities may have allowed genera to disperse over large distances and

237 sustain high mortality in search of patchy habitats which fit increasingly narrow environmental

238 preferences ${ }^{37}$. This would facilitate the development of $\alpha$ diversity in areas with enhanced

239 environmental heterogeneity by allowing animals to adopt narrower niches and coexist at higher

240 diversities, a prediction which may be supported by the positive correlation between $\alpha$ diversity

241 and the number of formations within grids.

243 However, easy dispersal also allows the development of a metacommunity from which

244 populations can be replenished after local extinction. This allows 'transient' taxa to persist and

245 contribute to $\alpha$ diversity over long timescales, despite lacking a competitive advantage in any

246 particular niche $e^{40-42}$. Where dispersal is easy, increased niche packing and an increase in the

247 prevalence of transient genera leave the same spatial diversity patterns (increased $\alpha$ diversity and

248 reduced $\beta$ diversity), and are not mutually exclusive processes, so we cannot directly quantify

249 their contributions in this case. However, the niche packing interpretation implies the ongoing

250 origination of new taxa with increasingly specialised habitat preferences, and the extinction of

251 pre-existing taxa, and so should be accompanied by high origination and extinction rates.

252 Instead, origination and extinction rates fell rapidly during the Late Cambrian-Early 
253 Ordovician ${ }^{43}$, suggesting that niche packing was not a dominant driver of increasing $\alpha$ diversity

254 after this time. Instead, we tentatively interpret the Ordovician-Silurian disjunct between $\beta$ and $\alpha$

255 diversity as a consequence of a major increase in transient species within grid cells, facilitated by

256 the increasing ease of dispersal after the evolution of planktotrophic larvae.

258 In sum, our results suggest a combination of mechanisms for the reported early Palaeozoic shift

259 from rising $\gamma$ diversity driven by $\beta$ diversity, to $\alpha$ diversity ${ }^{14}$. As expected, $\gamma$ diversity correlates

260 positively with both $\alpha$ and $\beta$ diversity over the Cambrian-Silurian, though the influence of $\beta$

261 diversity may have declined after the Ordovician, when $\gamma$ and $\alpha$ both rise while $\beta$ falls.

262 Environmental heterogeneity and faunal differentiation between environments appears to be an

263 important driver of both $\alpha$ and $\beta$ diversity, illustrated by positive correlations with the number of

264 formations within grids and lithological $\beta$ diversity, respectively. Our data are also consistent

265 with an important role for dispersal in driving both $\alpha$ and $\beta$ diversity patterns, with increased

266 dispersal from the late Cambrian leading to declining $\beta$ diversity and enhanced $\alpha$ diversity. This

267 combination of mechanisms may have altered global diversity dynamics and ecosystem

268 complexity by allowing taxa to adopt narrower niches, and, from the early Ordovician onwards,

269 allowing taxa with no competitive advantage to persist more easily. The result was a shift in the

270 mechanisms driving global diversification, from the maintenance of geographic $\beta$ diversity

271 through origination of young taxa with low dispersal abilities, to enhanced $\alpha$ diversity driven by

272 environmental and faunal differentiation at smaller spatial scales, geographic range expansion,

273 and an increase in the prevalence of transient genera.

274

275 Ongoing work is required to evaluate the relative impacts of palaeogeographic, 
276 palaeoenvironmental and evolutionary drivers on global diversity. $\alpha$ and $\beta$ diversity estimates at

277 varying scales and using a variety of approaches (spatial, environmental, and using indices which

278 focus on different aspects of faunal difference), can complement each other to clarify possible

279 drivers for global diversification in the early Palaeozoic. Furthermore, more studies of the

280 sedimentology and geochemistry of early Palaeozoic environments, and their interaction with

281 niche occupation in early Palaeozoic communities, are needed to unpick the smaller-scale

282 mechanisms driving community differentiation, niche packing, and taxon persistence over this

283 critical time interval.

284

285 Methods

286 We calculated $\alpha, \beta$ and $\gamma$ diversity for all time bins which contained at least four grid cells

287 containing ten fossil occurrences or more, of which at least two had to reach the coverage for

288 standardization (set to 0.4 ). We set the minimum number of occurrences to ten to reduce the

289 chance that null models would be built based on data which represented the abundance

290 distribution of their original populations poorly. Along with diversity measures, we also used

291 additive $\beta$ diversity partitioning to assess the contributions of nestedness and turnover to $\beta$

292 diversity, and calculated the mean nearest-neighbour great-circle distances between grid cell

293 centres using the $\mathrm{R}$ package icosa ${ }^{44}$.

294

295 We based our analysis on fossil occurrences of brachiopods, echinoderms, molluscs and

296 trilobites from the Paleobiology Database (PaleoBioDB), identified to genus level (downloaded

$29718^{\text {th }}$ January 2019, www.paleobiodb.org). Additional data were input to the database before this

298 study, and the PaleoBioDB is the most comprehensive fossil occurrence dataset available. 
Lagerstätten were removed, to minimize the impact of varying preservation quality between time

300 bins. All PaleoBioDB collections are linked to paleogeographic latitudinal and longitudinal

301 coordinates based on GPlates (https://www.gplates.org/) rotations ${ }^{45}$. We used the R package

$302 \operatorname{icosa}^{44}$ to assign fossil occurrences to equal-area hexagonal grid cells of side $111 \mathrm{~km}$, and treated

303 each grid cell as a single sample. Consequently, samples for $\alpha$ diversity calculation are composed

304 of fossils from an undifferentiated mix of depositional environments, and are also time-averaged

305 within time bins (see Supplementary Information Tables 2 and 3 for time bin boundaries). Grids

306 of side $222 \mathrm{~km}$ and $55 \mathrm{~km}$ gave similar $\beta$ diversity results (See Extended Data Figure 2).

307

308 The time bins are based on chronostratigraphic stages from the International Chronostratigraphic 309 Chart (v2018/08) ${ }^{46}$. The current PaleoBioDB chronostratigraphic binning scheme is less precise 310 and based on Gradstein et al. (2012) ${ }^{47}$, which caused some data loss during binning (such as the 311 data from Cambrian Stage 4 and the three Furongian stages). All PaleoBioDB occurrences that 312 have absolute time and/or chronostratigraphic stage assignments that fit within our time bin 313 scheme were taken into consideration for our analysis. However, time bin duration can influence

$314 \alpha, \beta$ and $\gamma$ diversity patterns, because the temporal turnover of species can artificially inflate

315 diversity in longer time bins ${ }^{20}$. Cambrian to Silurian stages in the PaleoBioDB binning scheme

316 range in duration from $11 \mathrm{Myr}$ in the Terreneuvian, to $1.4 \mathrm{Myr}$ in the Hirnantian. Mean time bin

317 durations in the Cambrian and Ordovician are similar to each other (5.8 and 5.9 Myr,

318 respectively), while Silurian time bins are shorter (3.1 Myr). To ensure that diversity

319 measurements were comparable between time periods, we amalgamated the shortest Silurian

320 time bins with their neighbouring bins (revised mean Silurian time bin length = 6.2 Myr),

321 reducing our number of time bins to 16 but limiting the impact of time bin length on results. This 
322 leaves the Silurian divided into four time bins: Rhuddanian-Aeronian, Telychian, Sheinwoodian-

323 Homerian and Gorstian-Ludfordian-Pridoli. Neither $\alpha, \beta$ nor $\gamma$ diversity shows a significant

324 correlation with revised time bin length (See Extended Data Table 1).

326 Coverage standardisation was used to reduce the impact of sampling effort and exposed rock

327 volume on the results ${ }^{48}$. This effect is especially pronounced in $\alpha$ and $\gamma$ diversity, but there is no

328 correlation between mean coverage and $\beta$ diversity, when no coverage standardisation is applied

329 (Kendall's $\tau=0.08, p=0.77$ ). However, because the relationship between $\alpha$ and $\beta$ is of interest,

330 we chose to coverage-standardise $\beta$ diversity for comparability with $\alpha$ diversity. Coverage

331 standardisation for $\gamma$ diversity estimates was done over whole time bins, rather than standardising

332 each grid cell separately. The standardisation coverage was set to 0.4 because this permitted $\beta$

333 diversity calculations for most of the time bins which met the minimum number of grid cells;

334 sensitivity analyses demonstrate that a standardization coverage of 0.2 or 0.5 does not

335 significantly change the results (See Extended Data Figure 3). Time bins were pre-screened in an

336 attempt to ensure that there would be enough data in the time bin for simulated datasets to pass

337 coverage standardization. When coverage for standardization is set to 0.5 , several additional time

338 bins do not contain enough data for analysis. The minimum number of grid cells for time bins to

339 be analysed was arbitrarily set to 4 , to remove data from time bins containing very few grid cells

340 which would have low spatial coverage.

342 ' $\beta$ diversity' may refer to any one of over twenty mathematical treatments of faunal difference,

343 with distinct sensitivities, biases and data types, and there are also conceptual differences in the

344 definition of $\beta$ diversity between studies ${ }^{49-53}$. For example, $\beta$-diversity can be measured across 
345 depositional environments ${ }^{1,38,54}$, between or within lithostratigraphic units ${ }^{14,27}$, or across pre346 defined sampling areas ${ }^{13,20}$. Here, we estimated global geographic $\beta$ diversity ${ }^{13}$ by calculating

347 pairwise Sørensen dissimilarities between equal-area grid cells using the R package vegan ${ }^{55}$.

$349 \beta$ diversity can be subdivided into turnover and nestedness components ${ }^{31}$. Nestedness reflects the 350 extent to which less diverse assemblages are subsets of more diverse ones, while turnover 351 reflects the extent to which taxa are replaced when assemblages are compared ${ }^{31}$. Because 352 nestedness and turnover result from differing processes (taxon loss and taxon replacement, 353 respectively), partitioning $\beta$ diversity into turnover and nestedness components can reveal 354 underlying drivers of assemblage difference, which are not obvious from a single $\beta$ diversity 355 measure ${ }^{56}$. The Sørensen dissimilarity incorporates both turnover and nestedness components of $356 \beta$ diversity; the nestedness component is calculated by subtracting the Simpson

357 dissimilarity ${ }^{51,57,58}$, which only measures turnover, from the Sørensen dissimilarity ${ }^{31,51,59}$. While 358 the R package betapart is designed for performing this procedure, we implemented it using 359 RACB.Diversity ()$^{60}$, which has an option to calculate the Simpson dissimilarity as re-expressed 360 by Lennon et al. (2001) ${ }^{57}$. Presence-absence diversity indices may be excessively influenced by 361 the presence of rare taxa, so we also calculated the abundance-based RAC Bray-Curtis 362 dissimilarity ${ }^{51,61}$, which was not significantly different from the Sørensen dissimilarity curve, 363 demonstrating that rare taxa are not a major influence on our results (See Extended Data Figure 364 4). The $\beta$ diversity between two communities ranges from 0 to 1 , where a value of 0 indicates 365 that the assemblages are identical, while a value of 1 indicates that the assemblages contain no 366 shared taxa. 
368 Many suggested drivers for early Palaeozoic diversifications involve an increased supply of

369 resources such as oxygen, nutrients, or chemical energy ${ }^{10,62}$, which may increase the abundance

370 of organisms ${ }^{63}$. Abundance influences diversity patterns because abundant taxa are more likely

371 to be preserved and sampled than rare ones ${ }^{64}$, and with incomplete sampling, abundance

372 distributions can alter apparent $\beta$ diversity ${ }^{60}$. Because of this, we used the Relative Abundance

373 Corrected (RAC) $\beta$ diversity between grid cells within time bins as a $\beta$ diversity measure,

374 because it corrects for spuriously high $\beta$ diversities caused by incomplete sampling, and because

375 it reduces the impact of changing abundance distributions on $\beta$ diversity ${ }^{60}$. Raw $\beta$ diversity

376 values recovered are considerably higher than the RAC values, which suggests that incomplete

377 sampling may increase apparent $\beta$ diversity values in the early Palaeozoic (See Extended Data

378 Figure 1). We used 100 replicates for simulations within RACB.Diversity(), and coverage-

379 standardised to Good's $\mathrm{u}=0.4$, to reduce the impact of uneven sampling on diversity estimates

380 and to ensure that $\alpha$ and $\beta$ diversity estimates are based on the same data.

382 Coverage-standardised $\alpha$ (within grid cell) and $\gamma$ diversities were calculated using the function 383 estimate $\mathrm{D}()$ in the $\mathrm{R}$ package $\mathrm{iNEXT}^{65}$, which calculates taxonomic diversity with a pre-defined

384 level of sample coverage (set to 0.4 , for comparability with $\beta$ diversity analyses). We excluded

385 extrapolations with suspected large biases from the means for each time bin. We used the mean

386 within-grid $\alpha$ diversity as a proxy for spatial niche packing ${ }^{1,17}$, based on the principle that two

387 taxa cannot coexist if they occupy the same ecological niche (Gause's principle of competitive

388 exclusion $^{66}$ ), and we extend this principle to the genus level.

390 The effects of sampling may be especially hard to interpret for $\beta$ diversity. The effect of exposed 
391 sedimentary rock volume on global diversity curves is well documented, though may have a

392 'common cause' with diversification ${ }^{67-69}$. Similarly, we might expect declining $\beta$ diversity values

393 in time bins with increasingly closely spaced samples. Therefore, we checked for correlations

394 between $\beta$ diversity and the number of grids in a time bin, and also between $\beta$ diversity and the

395 mean nearest-neighbour great circle distance between grid cell centres in a time bin (See

396 Extended Data Table 1).

397

398 The heterogeneity of environments within grid cells was evaluated using the mean number of

399 formations within grid cells, which we calculated after removing grid cells containing fewer than

400 ten fossil occurrences.

401

402 We checked for autocorrelation in all variables before calculating correlations between them

403 using the $\operatorname{acf}()$ function in $\mathrm{R}^{70}$. No variable showed autocorrelation (See Extended Data Figure

404 5), so we have not detrended data before checking for correlations. We used Kendall's $\tau$ as a

405 measure of correlation, and we set the critical value for significance at 0.1 , given the relatively

406 small sample size $(n=13$, once time bins with insufficient data are filtered out).

408 Code Availability

409 The complete code and relevant results are recorded in R-code and can be downloaded at

410 zenodo.org (DOI: 10.5281/zenodo.3463219).

\section{Acknowledgements}

413 This study was part of the Academy of Finland-funded project Ecological engineering as a 
414 biodiversity driver in deep time. We offer sincere thanks to Susan Scholze for data entry into the

415 Paleobiology Database over the course of this study, to Matthew Wale for help with running

416 sensitivity analyses, and to Richard Hofmann for helpful discussions on $\beta$ diversity in the

417 Palaeozoic. This is a contribution to IGCP 653, "The onset of the Great Ordovician

418 Biodiversification Event”.

419

420 Author Contributions

421 AP and BK devised this research, agreed on analytical techniques, and wrote the paper together.

422 AP calculated $\beta$ diversity and checked correlations. BK downloaded and formatted data from the

423 Paleobiology Database, calculated $\alpha$ and $\gamma$ diversity, and drew the figures.

424

425 Data Availability

426 All data used in this work can be downloaded from the Paleobiology Database

427 (https://paleobiodb.org/\#/). URLs for retrieving the data used to generate these results are

428 available in the accompanying code (see 'Code Availability').

429

430 Competing Interests

431 The authors declare no competing interests.

\section{References}

434 1. Sepkoski, J. J. Alpha, Beta, or Gamma: Where does all the diversity go? Paleobiology 14, $435 \quad 221-234(1988)$.

436 2. Servais, T., Owen, A. W., Harper, D. A. T., Kröger, B. \& Munnecke, A. The Great 437 Ordovician Biodiversification Event (GOBE): The palaeoecological dimension. 
Palaeogeogr. Palaeoclimatol. Palaeoecol. 294, 99-119 (2010).

439 3. Servais, T. et al. The onset of the 'Ordovician Plankton Revolution' in the late Cambrian.

$440 \quad$ Palaeogeogr. Palaeoclimatol. Palaeoecol. 458, 12-28 (2016).

441 4. Smith, M. P. \& Harper, D. A. T. Causes of the Cambrian Explosion. Science. 341, 1355-6

442 (2013).

443 5. Harper, D. A. T. The Ordovician biodiversification: setting an agenda for marine life. 232, $444 \quad 148-166(2006)$.

445 6. Droser, M. L. \& Finnegan, S. The Ordovician Radiation: a follow-up to the Cambrian 446 Explosion? Integr. Comp. Biol. 43, 178-184 (2003).

447 7. Rasmussen, C. M. Ø., Kröger, B., Nielsen, M. L. \& Colmenar, J. Cascading trend of Early 448 Paleozoic marine radiations paused by Late Ordovician extinctions. Proc. Natl. Acad. Sci. $449 \quad$ 116, 7207-7213 (2019).

450 8. Servais, T. \& Harper, D. A. T. The Great Ordovician Biodiversification Event (GOBE): 451 definition, concept and duration. Lethaia 51, 151-164 (2018).

452 9. Webby, B. D., Paris, F., Droser, M. L. \& Percival, I. G. The Great Ordovician 453 Biodiversification Event. (Columbia University Press, 2004).

454 10. Stigall, A. L., Edwards, C. T., Freeman, R. L. \& Rasmussen, C. M. Ø. Coordinated biotic 455 and abiotic change during the Great Ordovician Biodiversification Event: Darriwilian 456 assembly of early Paleozoic building blocks. Palaeogeogr. Palaeoclimatol. Palaeoecol. $457 \quad$ 530, 249-270 (2019).

458 11. Erwin, D. H. \& Valentine, J. W. The Cambrian Explosion: the construction of animal 459 biodiversity. (Roberts and Company Publishers, 2013).

460 12. Stigall, A. L. Ordovician oxygen and biodiversity. Nat. Geosci. 10, 883-888 (2017). 
461 13. Na, L. \& Kiessling, W. Diversity partitioning during the Cambrian radiation. Proc. Natl. $462 \quad$ Acad. Sci. 112, 4702-4706 (2015).

463 14. Hofmann, R., Tietje, M. \& Aberhan, M. Diversity partitioning in Phanerozoic benthic 464 marine communities. Proc. Natl. Acad. Sci. 116, 79-83 (2019).

465 15. Miller, A. I. Dissecting global diversity patterns: examples from the Ordovician Radiation. 466 Апnu. Rev. Ecol. Syst. 28, 85-104 (1997).

467 16. Jost, L. Partitioning diversity into independent alpha and beta components. Ecology 88, $468 \quad 2427-2439(2007)$.

469 17. Harper, D. A. T. The Ordovician brachiopod radiation: roles of alpha, beta, and gamma 470 diversity. Geol. Soc. Am. Spec. Pap. 466, (2010).

471 18. Alroy, J. et al. Phanerozoic trends in the global diversity of marine invertebrates. Science $472 \quad 321,97-100(2008)$.

473 19. Hautmann, M. Diversification and diversity partitioning. Paleobiology 40, 162-176 $474 \quad$ (2014).

475 20. Miller, A. I. et al. Phanerozoic trends in the global geographic disparity of marine biotas. $476 \quad$ Paleobiology 35, 612-630 (2009).

477 21. Stigall, A. L. How is biodiversity produced? Examining speciation processes during the $478 \quad$ GOBE. Lethaia 51, 165-172 (2018).

479 22. Stigall, A. L., Bauer, J. E., Lam, A. R. \& Wright, D. F. Biotic immigration events, 480 speciation, and the accumulation of biodiversity in the fossil record. Glob. Planet. Change $481 \quad \mathbf{1 4 8}, 242-257(2017)$.

482 23. Miller, A. I. A new look at age and area: the geographic and environmental expansion of 483 genera during the Ordovician radiation. Paleobiology 23, 410-419 (1997). 
484 24. Miller, A. I. \& Mao, S. Scales of diversification and the Ordovician radiation. in

485 Biodiversity dynamics: turnover of populations, Taxa, and Communities (eds. McKinney,

486 M. L. \& Drake, J. A.) 552 (Columbia University Press, 2001).

487 25. Zaffos, A., Finnegan, S. \& Peters, S. E. Plate tectonic regulation of global marine animal 488 diversity. Proc. Natl. Acad. Sci. 114, 5653-5658 (2017).

489 26. Kröger, B. Changes in the latitudinal diversity gradient during the Great Ordovician 490 Biodiversification Event. Geology 46, 44-47 (2017).

491 27. Darroch, S. A. F. \& Wagner, P. J. Response of beta diversity to pulses of Ordovician492 Silurian mass extinction. Ecology 96, 532-549 (2015).

493 28. Kröger, B. \& Lintulaakso, K. RNames, a stratigraphical database designed for the 494 statistical analysis of fossil occurrences-the Ordovician diversification as a case study. 495 Palaeontol. Electron. 20, 1-12 (2017).

496 29. Jaanusson, V. \& Bergström, S. M. Middle Ordovician faunal spatial differentiation in 497 Baltoscandia and the Appalachians. Alcheringa 4, 89-110 (1980).

498 30. Kröger, B. Cambrian - Ordovician cephalopod palaeogeography and diversity. in Early 499 Palaeozoic biogeography and palaeogeography, Geological Society, London, Memoirs $500 \quad 38,429-448(2013)$.

501 31. Baselga, A. Partitioning the turnover and nestedness components of beta diversity. Glob. 502 Ecol. Biogeogr. 19, 134-143 (2010).

503 32. Harper, D. A. T. \& Servais, T. Early Palaeozoic biogeography and palaeogeography: towards a modern synthesis. in Geological Society, London, Memoirs, Volume 38(1) (eds. Harper, D. A. T. \& Servais, T.) 1-4 (2013).

506 33. Harper, D. A. T. et al. Biodiversity, biogeography and phylogeography of Ordovician 
rhynchonelliform brachiopods. in Early Palaeozoic Biogeography and Palaeogeography. (2013).

$51034 . \quad$ Cocks, L. R. M. \& Fortey, R. A. Biogeography of Ordovician and Silurian faunas. in Palaeozoic Palaeogeography and Biogeography, Geological Society Memoir (eds.

McKerrow, W. S. \& Scotese, C. R.) 97-104 (1990).

513 35. Nützel, A., Lehnert, O. \& Frýda, J. Origin of planktotrophy- evidence from early molluscs. Evol. Dev. 8, 325-330 (2006).

515 36. Peterson, K. J. Macroevolutionary interplay between planktic larvae and benthic predators. Geology 33, 929-932 (2005).

517 37. Jablonski, D. \& Lutz, R. A. Larval ecology of marine benthic invertebrates: Paleobiological implications. Biol. Rev. 58, 21-89 (1983).

519 38. Lam, A. R., Stigall, A. L. \& Matzke, N. J. Dispersal in the Ordovician: Speciation patterns 520 and paleobiogeographic analyses of brachiopods and trilobites. Palaeogeogr. Palaeoclimatol. Palaeoecol. (2017). doi:10.1016/j.palaeo.2017.10.006

522 39. Kröger, B. \& Aubrechtová, M. The cephalopods of the Kullsberg Limestone Formation, Upper Ordovician, central Sweden and the effects of reef diversification on cephalopod diversity. J. Syst. Palaeontol. 0, 1-35 (2019).

40. McPeek, M. A. The macroevolutionary consequences of ecological differences among species. Palaeontology 50, 111-129 (2007).

41. McPeek, M. A. The ecological dynamics of clade diversification and community assembly. Am. Nat. 172, E270-E284 (2008).

42. Leibold, M. A. \& McPeek, M. A. Coexistence of the niche and neutral perspectives in 
community ecology. Ecology 87, 1399-1410 (2006).

531 43. Kröger, B., Franeck, F. \& Rasmussen, C. М. Ø. The evolutionary dynamics of the early Palaeozoic marine biodiversity accumulation. Proc. R. Soc. B Biol. Sci. 286, 20191634 (2019).

534 44. Kocsis, Á. T. icosa: Global Triangular and Penta-Hexagonal Grids Based on Tessellated Icosahedra, v. 0.9.81. (2017). Available at: https://cran.rproject.org/web/packages/icosa/index.html. (Accessed: 13th July 2019)

45. Wright, N. M., Zahirovic, S. \& Seton, M. Towards community-driven paleogeographic reconstructions: Integrating open-access paleogeographic and paleobiology data with plate tectonics. Biogeosciences 10, 1529-1541 (2013).

540 46. Cohen, K. M., Harper, D. A. T. \& Gibbard, P. L. ICS International Chronostratigraphic Chart (v2018/08). International Commission on Stratigraphy, IUGS (2018). Available at: http://www.stratigraphy.org. (Accessed: 12th December 2018)

543 47. Gradstein, F., Ogg, J., Schmitz, M. \& Ogg, G. The Geologic Timescale (2012). doi:10.1017/CBO9781107415324.004

545 48. Alroy, J. Fair sampling of taxonomic richness and unbiased estimation of origination and extinction rates. Paleontol. Soc. Pap. 16, 55-80 (2010).

547 49. Tuomisto, H. A diversity of beta diversities: straightening up a concept gone awry. Part 2. Quantifying beta diversity and related phenomena. Ecography 33, 23-45 (2010).

549 50. Tuomisto, H. A diversity of beta diversities: Straightening up a concept gone awry. Part 1. 550 Defining beta diversity as a function of alpha and gamma diversity. Ecography 33, 2-22 (2010).

552 51. Koleff, P., Gaston, K. J. \& Lennon, J. J. Measuring beta diversity for presence-absence 
data. J. Anim. Ecol. 72, 367-382 (2003).

554 52. Barwell, L. J., Isaac, N. J. B. \& Kunin, W. E. Measuring $\beta$ - diversity with species 555 abundance data. J. Anim. Ecol. 84, 1112-1122 (2015).

556 53. Anderson, M. J. et al. Navigating the multiple meanings of $\beta$ diversity: a roadmap for the practicing ecologist. Ecol. Lett. 14, 19-28 (2011).

558 54. Patzkowsky, M. E. \& Holland, S. M. Diversity partitioning of a Late Ordovician marine biotic invasion: Controls on diversity in regional ecosystems. Paleobiology 33, 295-309 (2007).

561 55. Oksanen, A. J. et al. vegan: Community Ecology Package. R package version 2.5.2 (2018). https://CRAN.R-project.org/package=vegan

563 56. Wright, D. H. A comparative analysis of nested subset patterns of species composition. Oecologia 113, 1-20 (1998).

565 57. Lennon, J. J., Koleff, P., Greenwood, J. J. D. \& Gaston, K. J. The geographical structure of British bird distributions: diversity, spatial turnover and scale. J. Anim. Ecol. 70, 966979 (2001).

568 58. Simpson, G. G. Mammals and the nature of continents. Am. J. Sci. 241, 1-31 (1943).

569 59. Sørensen, T. A. A method of establishing groups of equal amplitude in plant sociology

570 based on similarity of species content, and its application to analyses of the vegetation on 571 Danish commons. K. Danske Vidensk. Selsk. Biol. Skr. 5, 1-34 (1948).

572 60. Brocklehurst, N., Day, M. O. \& Fröbisch, J. Accounting for differences in species 573 frequency distributions when calculating beta diversity in the fossil record. Methods Ecol. Evol. 1409-1420 (2018). doi:10.1111/2041-210X.13007

575 61. Bray, J. R. \& Curtis, J. T. An Ordination of the upland forest communities of southern 
Wisconsin. Ecol. Monogr. 27, 325-349 (1957).

577 62. Edwards, C. T., Saltzman, M. R., Royer, D. L. \& Fike, D. A. Oxygenation as a driver of the Great Ordovician Biodiversification Event. Nat. Geosci. 10, 925-929 (2017).

579 63. Clarke, A. \& Gaston, K. J. Climate, energy and diversity. Proc. R. Soc. B Biol. Sci. 273, 2257-2266 (2006).

581 64. Hull, P. M., Darroch, S. A. F. \& Erwin, D. H. Rarity in mass extinctions and the future of ecosystems. Nature 528, 345-351 (2015).

65. Hsieh, T. C., Ma, K. H. \& Chao, A. iNEXT: an R package for rarefaction and extrapolation of species diversity (Hill numbers). Methods Ecol. Evol. 7, 1451-1456 (2016).

66. Hardin, G. The Competitive Exclusion Principle. Sci. New Ser. 131, 1292-1297 (1960).

67. Peters, S. E. \& Foote, M. Determinants of extinction in the fossil record. Nature 416, 420424 (2002).

68. Peters, S. E. Geologic constraints on the macroevolutionary history of marine animals. Proc. Natl. Acad. Sci. 102, 12326-12331 (2005).

69. Smith, A. B. \& McGowan, A. J. How much can be predicted from the sedimentary rock record of western Europe? Palaeontology 50, 765-774 (2007).

593 70. R Core Team (2018). R: A language and environment for statistical computing. R Foundation for Statistical Computing, Vienna, Austria. https://www.R-project.org/. 
599 The following abbreviations are used for stratigraphic names: Terr $=$ Terreneuvian, $\mathrm{Se} 2=$

600 Cambrian Series 2, Mia $=$ Miaolingian, $\mathrm{Fu}=$ Furongian, $\mathrm{Tr}=$ Tremadocian, $\mathrm{Fl}=$ Floian, $\mathrm{Dp}=$

601 Dapingian, $\mathrm{Dw}=$ Darriwilian, $\mathrm{Sb}=$ Sandbian, $\mathrm{Ka}=\mathrm{Katian}, \mathrm{Hi}=$ Hirnantian, $\mathrm{Rh}=$ Rhuddanian,

$602 \mathrm{Ae}=$ Aeronian, $\mathrm{Tl}=$ Telychian, $\mathrm{Sh}=$ Sheinwoodian, $\mathrm{Ho}=$ Homerian, $\mathrm{Go}=$ Gorstian, $\mathrm{Lu}=$

603 Ludfordian, $\operatorname{Pr}=$ Pridoli, Lo = Lochkovian.

604 a. Global $(\gamma)$ diversity, showing a peak during the Darriwilian, during the main pulse of the 605 GOBE.

606 b. Geographic $\beta$ diversity measured using the RAC Sørensen dissimilarity.

607 c. Mean $\alpha$ diversity.

608 In all figures, 95\% confidence intervals are shown in orange. All metrics are coverage-

609 standardised to Good's u = 0.4. The Cambrian Explosion (CE) extends from approximately 530-

$610520 \mathrm{Ma}^{11}$, while the Great Ordovician Biodiversification Event (GOBE) extends throughout the

611 Ordovician $^{8}$.

612

613 Figure 2. Heterogeneity of lithological units within grids, and nestedness from 540-419 Ma

614 The following abbreviations are used for stratigraphic names: Terr $=$ Terreneuvian, $\mathrm{Se} 2=$

615 Cambrian Series 2, Mia $=$ Miaolingian, $\mathrm{Fu}=$ Furongian, $\mathrm{Tr}=$ Tremadocian, $\mathrm{Fl}=\mathrm{Floian}, \mathrm{Dp}=$

616 Dapingian, $\mathrm{Dw}=$ Darriwilian, $\mathrm{Sb}=$ Sandbian, $\mathrm{Ka}=\mathrm{Katian}, \mathrm{Hi}=$ Hirnantian, $\mathrm{Rh}=$ Rhuddanian,

$617 \mathrm{Ae}=$ Aeronian, $\mathrm{Tl}=$ Telychian, $\mathrm{Sh}=$ Sheinwoodian, $\mathrm{Ho}=$ Homerian, $\mathrm{Go}=$ Gorstian, $\mathrm{Lu}=$

618 Ludfordian, $\operatorname{Pr}=$ Pridoli, Lo = Lochkovian.

619 a. Mean number of formation within grids, used as a measure of environmental heterogeneity.

620 b. Nestedness, calculated by subtracting the RAC Simpson dissimilarity from the RAC Sørensen

621 dissimilarity. 
623 Figure 3. Relationship between within-grid alpha diversity and within-grid number of

624 formations.

$625 \quad$ Kendall's $\tau=0.53, \mathrm{p}=0.01$

626

627 
b

$\beta$ diversity

른

$\infty$.

至 0

ㅇำ-

t

Фं

ㄴ.

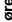

c.

c
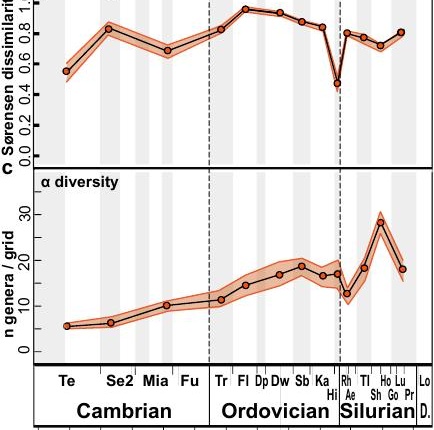

my $540 \begin{array}{llllllllllll}530 & 520 & 510 & 500 & 490 & 480 & 470 & 460 & 450 & 440 & 430 & 420\end{array}$ 


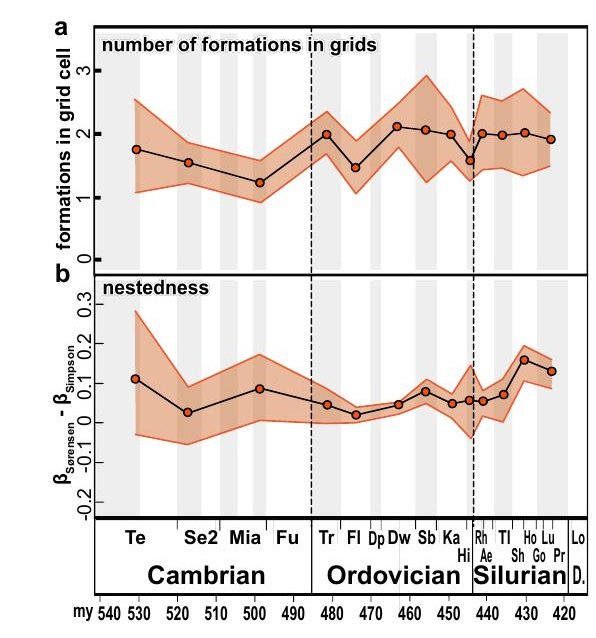


Relationship between within-grid alpha diversity and number of formations

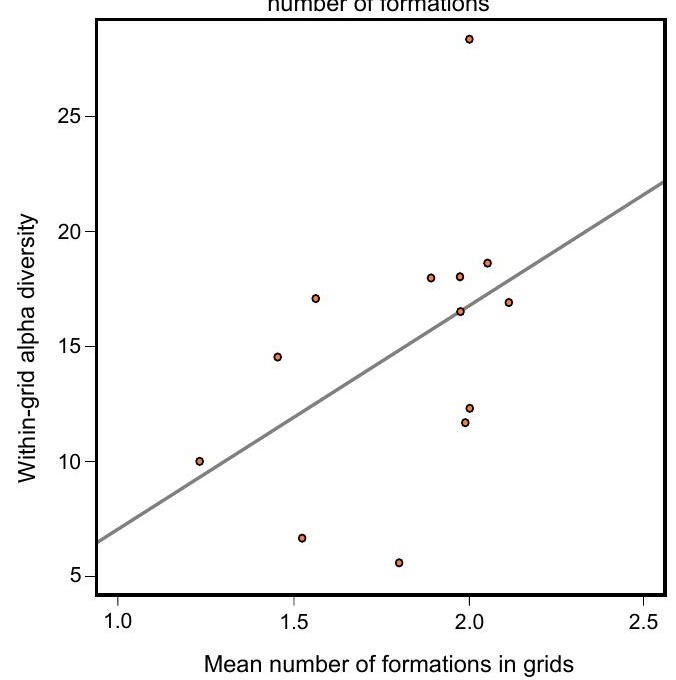

